\title{
THE ISSUE OF AGGRESSION IN PATIENTS WITH VENTRICULAR TACHYCARDIA WITH PULSE AND A SHORT EPISODE OF CARDIAC ARREST - A CASE OF A 68-YEAR-OLD MALE
}

\author{
Tomasz Kulpok-Baginski ${ }^{1}$, Klaudiusz Nadolny ${ }^{2,3}$, Jerzy Robert Ladny ${ }^{3}$, Sergiy Fedorov ${ }^{4}$, \\ Nataliya Izhytska ${ }^{5}$, Anna Rej-Kietla ${ }^{6}$, Lukasz Szarpak ${ }^{3,7}$, Daniel Slezak ${ }^{8}$ \\ ${ }^{1}$ Institute of Public Health, Faculty of Public Health, Medical University of Silesia in Katowice; \\ Emergency Room of Provincial Specialist Hospital No. 3 in Rybnik, Poland \\ ${ }^{2}$ Provincial Rescue Service in Katowice, Poland \\ ${ }^{3}$ Department of Emergency Medicine and Disasters, Medical University of Bialystok, Poland \\ ${ }^{4}$ Ivano-Frankivsk National Medical University, Ivano-Frankivsk, Ukraine \\ ${ }^{5}$ Danylo Halytsky Lviv National Medical University, Ukraine \\ ${ }^{6}$ Attorney's Office of Knapek, Rybczyński, Szmit and Partners, Poland \\ ${ }^{7}$ Department of Emergency Medicine, Medical University of Warsaw, Poland \\ ${ }^{8}$ Medical University of Gdańsk, Gdańsk, Poland
}

\begin{abstract}
INTRODUCTION: Ventricular tachycardia (VT) is a life-threatening event. The role of the medical rescue team is to diagnose this disorder on the basis of resuscitation guidelines and general recommendations concerning ECG diagnoses. Patients with ventricular tachycardia, as a result of cerebral hypoxia, may react with aggression. In such situations, taking one's medical history, conducting a physical examination or attempting emergency rescue operations may become difficult, or even impossible.
\end{abstract}

OBJECTIVE: The objective of the paper is to demonstrate the issue of unintentional aggression that may occur in patients with ventricular tachycardia (VT) with a high heart rate and a short episode of cardiac arrest (CA), and the impact of such a disorder on attempted medical rescue operations.

MATERIAL AND METHODS: The analysis of the case study was performed on the basis of medical documentation, i.e. an emergency dispatch order and an emergency medical services form.

CASE DESCRIPTION: A medical emergency unit stationed at one of the substations in Łódź Province, $27 \mathrm{~km}$ away from a multi-disciplinary hospital, received a call from a medical dispatcher. The person calling emergency services requested the urgent arrival of an ambulance for her husband, who had suddenly passed out and was now lying on the kitchen floor showing no signs of life. In the course of the ambulance's arrival at the location, the patient's wife urged the ambulance to arrive soon, on account of her husband's aggressive behaviour.

CONCLUSIONS: Cardiac dysrhythmia and particularly ventricular tachycardia (VT) may constitute a serious health issue for the patient. The clinical picture may also vary across patients. An analysis of the case study demonstrates that medical personnel must be prepared to handle unconventional scenarios. The article shows that the procedure of cardioversion may be the only right choice when handling a patient with an unstable tachycardia.

KEY WORDS: cardiac arrest, cardiac dysrhythmia, emergency medicine, emergency medical service, ventricular tachycardia, VT, aggression

Disaster Emerg Med J 2017; 2(4): 167-172 


\section{INTRODUCTION}

Ventricular arrhythmias are the most common cause of cardiac arrest [1]. Ventricular tachycardia (VT) is a rhythm of ventricular origin with a frequency of at least 100/min [2]. Defibrillation rhythms, including ventricular fibrillation (VF) and pulseless ventricular tachycardia ( $\mathrm{pVT}$ ) constitute the most frequent mechanism of CA [3].

In the absence of such data, the percentage of patients who experience $\mathrm{VT}$ and the number of cases ending in a CA cannot be determined. Two basic types of ventricular tachycardia can be differentiated. One of them is an unchanged QRS complex (the so-called monomorphic VT), while the other displays a change in the axis of QRS complexes (the so-called polymorphic VT, torsade de pointes). The term torsade de pointes was first used by Dessertenne to describe a new ventricular arrhythmia with abnormal characteristics [4]. In both cases the pulse is still detectable. Additionally, two more types of arrhythmia are distinguished on account of their duration: transient tachycardia (at least 3 QRS complexes) and sustained tachycardia, with a duration of at least 30 seconds when VT occurs alternately with a sinus rhythm. The diagnosis of life-threatening cardiac dysrhythmias, which include ventricular tachyarrhythmia, may protect the patient against cardiac arrest and death. VT constitutes a direct threat to a patient's life. The clinical picture of VT is relatively mild. The vast majority of patients experience only such symptoms as palpitation, whereas a minority of patients suffer from a loss of consciousness [5]. In over half of the patients treated for recurring ventricular tachycardia, the initial cause is ischaemic heart disease. A post-infarction scar with living tissue may restrict the heart area and release the so-called re-entry mechanism as one of the most frequent causes of VT. This happens because of delaying conductibility in this area of the heart, while establishing at the same time the so-called re-entry wave slow part. Other reasons for tachycardia include: dilated cardiomiopathy and hypertrophic cardiomyopathy, mitral valve prolapse, valvular defects, and congenital heart defects [6]. The ABCDE trial is the basic diagnostic tool in the hands of every paramedic working in the field of emergency medical services. Evaluation of the circulation factor, including an ECG recording, is a basic element of a patient's examination in pre-hospital care. The VT diagnosis is chiefly based on the ECG recording. Basic ECG criteria of the diagnosis include: extension of the QRS complex over 0.12 s; atrioventricular dissociation; and QRS morphology. Signs of the ventricular origin of the arrhythmia include: QRS complexes with the features of right bundle branch block in the V1 lead, single-phase with wide and high $\mathrm{R}$ wave, two-phased type qR, or RS, or Rsr; QRS complexes with the features left bundle branch block with widened and low $\mathrm{R}$ wave in $\mathrm{V} 1$; the consistent and positive direction of QRS complexes in V1-V6 leads; and QS complexes in II, III, aVF or V5-V6 [7]. Gradual cerebral hypoxia is caused as a result of haemodynamic instability features in a VT patient. This may manifest itself by features of hypoxia and changes in consciousness in a patient. Following the low cardiac output in the course of VT, consciousness disorders may manifest themselves ranging from excessive sluggishness to extreme aggression in a patient, even towards the team of paramedics. The ability to act quickly, especially conducting a quick diagnosis of VT and the implementation of the right type of treatment, becomes a race against time in which the life of a patient becomes the supreme goal. Patient's ability of self-determination and conscious decision-making may be restricted through progressing consciousness disturbance. The role of quick diagnosis in emergency medicine and firm and resolute actions become invaluable. The ability to communicate in a team, cooperation with the patient's family, their confidence in the team's actions all become key elements in emergency rescue operations. Aggression, which is consequent upon the patient's cerebral hypoxia, impedes the implementation of life-saving procedures, such as electrical cardioversion or cannulation for the purpose of administering analgosedation or antiarrhythmic drugs. The question remains whether, and to what degree a patient with the features of haemodynamic instability following VT with a low cardiac output remains conscious of their life-threatening situation. Other questions which also seem to be crucial are: is the patient conscious of the fact that their life is in danger?; does their aggressive behaviour follow only from cerebral hypoxia caused by faster heart rate, or perhaps there are other causes of this condition?; why do some VT patients react by confusion, while others react by loss of consciousness or excitation?

\section{REENTRANT EXCITATION AS THE MAIN CAUSE OF VT}

The automation of conductivity means that the fibres of heart tissue spontaneously generate excitation. The electrical conduction system of the heart is composed of 3 main pacemakers: the SA node 


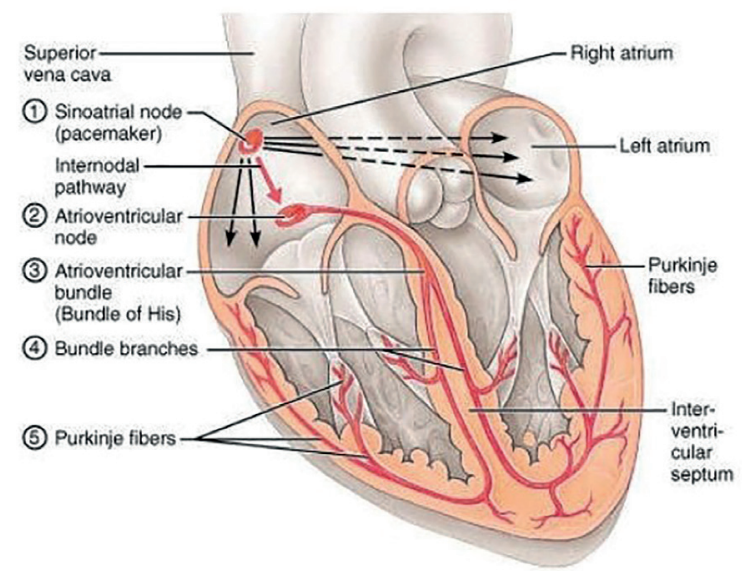

FIGURE 1. Conduction system of the heart

(lat. nodus sinuatrialis,), the AV node (lat. nodus atrioventicularis,) and the bundle of His (Fig. 1) [8].

The phenomenon of excitation disorders called the re-entrant mechanism, which is the main cause of $V T$, is the consequence of a scar or ischaemia in the heart. The scar or the ischaemia may cause the areas of the heart with heterogeneous conductivity to occur. When conductivity reaches the area that has been repolarised after previous depolarisation, the circuit of re-entrant excitation may occur which will induce sustained tachyarrhythmias such as VT. The phenomenon of re-entry consists in the presence of three basic elements:

- the existence of two pathways of conductivity which are functionally separate;

- a one-directional conductivity block in one of these pathways;

- a difference in conductivity speed between the pathways - slow conductivity in one pathway and excitation re-entry in the other.

\section{THE LEGAL ASPECT OF IMPLEMENTING MEDICAL RESCUE OPERATIONS BY PARAMEDICS IN THE OCCURRENCE OF VT WITH PULSE}

The scope of rights and qualifications of a paramedic is defined by two legal acts: The National Medical Rescue Service Act of 8 September 2006 (as amended, Journal of Laws 2006 no. 191, item 1410) and the Regulation of the Minister of Health of 20 April 2016, item 587, on medical rescue operations and health services other than rescue operations which may be provided by the paramedic. The Regulation of the Minister of Health of 20 April 2016, in section 12, introduces the possibility of performing electrical cardioversion in tachyarrhythmias in the case of patients who are haemodynamically unstable [9]. The case of a man with VT with pulse and a short episode of CA described below took place before the new regulations, which enabled the performance of electrical cardioversion, were in force.

\section{CASE STUDY OF A 68-YEAR-OLD MALE PATIENT WITH VT AND PULSE}

$A$ " $P$ " medical emergency unit (EMS P) stationed at one of the substations in Łódź Province, $27 \mathrm{~km}$ away from a multi-disciplinary hospital, received a call from a medical dispatcher. The person calling for emergency requested the urgent arrival of an ambulance for her husband, who had suddenly passed out and was now lying on the kitchen floor showing no signs of life. The patient's wife was very agitated; she urged the ambulance to arrive soon while it was en route, as the patient was excited and aggressive.

While taking the medical history, the dispatcher sent the nearest available ambulance to the event location (EMS P). In order to shorten the time of reaching the patient, the information was dispatched to the rescue team by a radio message. The dispatcher remained on the phone with the patient's wife, instructing her and providing all the necessary information until the ambulance arrived at the location of the event.

\section{Approximate hours}

- Starting time of the request: 10:19:42;

- Time of decision to send the medical rescue team: 10:20:10 (28 seconds following the starting time of request);

- The time of the team's arrival on the event location: 10:22:30 (after 2 minutes and 20 seconds);

- The distance between the place of request and the base station of the medical rescue team (according to GPS coordinates): $1.3 \mathrm{~km}$.

\section{The composition of medical rescue team}

Paramedic - leader (professional experience of 11 years); second paramedic (professional experience of 10 years); driver with a completed qualified first aid course who is also a professional fireman.

\section{The description of the location of the event}

The patient was on the first floor of a block of flats with a narrow stairway, lying on the kitchen floor, with kitchenware visibly upset and the table moved 
aside (perhaps as a result of the patient's fall onto the ground).

\section{Preliminary findings as regards the event (wife's account)}

The husband went to the kitchen to prepare a mid-morning snack. He suddenly felt bad, quickly sat down on the floor and lost consciousness. After a while he regained consciousness but was confused for a short moment. Then he became aggressive and started uttering incomprehensible sentences and when he tried to stand up he upset the kitchen table.

\section{Description of the visit and the proceedings of the medical rescue team}

Safety evaluation + first impression (SOS triangle) — patient breathes but wheezes, the chest moves, skin livid, central cyanosis, the patient does not move, does not make sounds, eyes closed.

\section{Medical history and physical examination}

On the AVPU scale - does not react to a pain stimulus, deeply unconscious $(U)$.

A - respiratory tract obstructed - establishing clear airways manually until the endotracheal tube is inserted;

B - respiration - 12/min, the chest lifts symmetrically, $\mathrm{SaO} 272 \%$, visible central cyanosis, decision to put on an oxygen mask with a reservoir, FiO2 15l/min, auscultation - single bilateral wheezes in both lungs (information from the patient's wife about COPD and the antibiotic treatment with amoxicillin that finished 7 days before, in the course of bronchitis);

C - pulse approx. 70/min on the central artery (carotid artery), no pulse felt on peripheral arteries (radial artery and brachial artery), BP unmeasurable, CRT prolonged to 5-6 s, skin livid all over the body.

The examination is interrupted at this point. The patient starts sitting up, removes the endotracheal tube with his hands. The team tries to calm him down but the patient becomes very aggressive and does not allow himself to be touched. He stands up suddenly and tries to pass through to the living room. He asks about what happened and why the ambulance has arrived. The paramedic tries to explain to the patient that he has lost consciousness. The team leader asks the patient not to stand up, but the patient disregards his request, rises and moves to the adjacent room while being assisted, and sits on the couch. He is confused and agitated. He does not wish to speak to the medical rescue team, nor does he listen to his wife. He claims that he feels well and that everything is alright with him.

While the paramedics are trying to explain to the patient what has happened, the team leader collects his medical history focusing in particular on the course of the event. The patient is asked a question about any pains or feeling unwell just before the loss of consciousness. The patient negates feeling badly. He does not wish to continue the conversation, and rips away the oxygen mask from his face. He becomes increasingly agitated and aggressive. The medical rescue team makes a decision to call team $\mathrm{S}$ (EMS S) for assistance (ambulance with a doctor). The distance of EMS S to the event location is $29 \mathrm{~km}$. The information from the dispatcher: the team with a doctor is busy providing medical assistance to another patient. They will arrive the event location when their intervention has finished. The team make a decision to make another attempt at conducting basic examinations while calming down the patient. The patient calms down and agrees to continue the treatment with an oxygen mask started previously. The team conduct the $A B C D E$ trail.

A - airways unobstructed;

B - respiration 16/min, SaO2 90\%, skin pale, no signs of central cyanosis, slight facial cyanosis, minor wheezes over lung fields;

C - pulse felt on the carotid artery approx. 70/min, no pulse felt on the radial artery, the second paramedic starts the ECG monitoring on II lead. Visible sinus rhythm 68/min, BP - unidentifiable.

At this juncture the examination is interrupted as the patient loses consciousness again (in a sitting position on the couch). The evaluation of basic vital parameters began.

On the AVPU scale - $\mathbf{U}$.

A - obstructed, wheezy respiration, decision to clear the airways manually until the Guedel tube is re-inserted;

B - respiration 16/min, SpO2 90\%, no changes on auscultation, the leader's decision - continuous treatment with an oxygen mask FiO2 15l/min;

C - HR on the carotid artery approx. 70/min, no pulse felt on the radial artery, CRT up to $3 \mathrm{~s}$, in the meantime iv access obtained (18 G cannula, green), the leader's decision to start fluid therapy. Connecting the $0.9 \%$ solution of $\mathrm{NaCl} 1000 \mathrm{ml}$, constant ECG monitoring on the II lead. At this moment, the presence of VT ok 160-180/min was observed on 
the patient monitor, a pulse on the carotid artery proves its presence.

The patient becomes excited again after a short while (about 5-10 seconds, and loses consciousness again. Another $A B C$ evaluation: deeply unconscious, B - no respiration, SaO2 ok. 85\%; C - no pulse in the carotid and radial arteries. Chest compressions and bag valve mask ventilation are initiated (short CPR 30:2 until the CA rhythm is confirmed), preparation for defibrillation (attempt to shave hair from the chest). At this point the patient starts moving slightly and regains consciousness, trying to remove the cannula from the arm. The monitor shows the rhythm to be slowing down to $140 /$ min, steady rhythm, wide QRS. A decision is taken to administer Cordarone $300 \mathrm{mg}$ iv in $250 \mathrm{ml}$ of glucose, intravenous infusion over the duration of about 10 minutes + the continuation of the fluid therapy initiated earlier. The patient is again agitated, but slightly less so than previously. He refuses to undergo the treatment, and claims that the arrival of the rescue team is not necessary. He tries to sit up at any cost. The patient sits up on the couch despite being held down (the body weight of the patient is worth emphasising at around $150 \mathrm{~kg}$ ).

Having conferred for a short while, the team perform a 12-lead ECG (Fig. 2). Blood pressure is identified at $80 / 65 \mathrm{~mm} \mathrm{Hg}$, SaO2 $96 \%$, the patient reports no pain. He agrees to be examined and taken to hospital. The oxygen therapy of
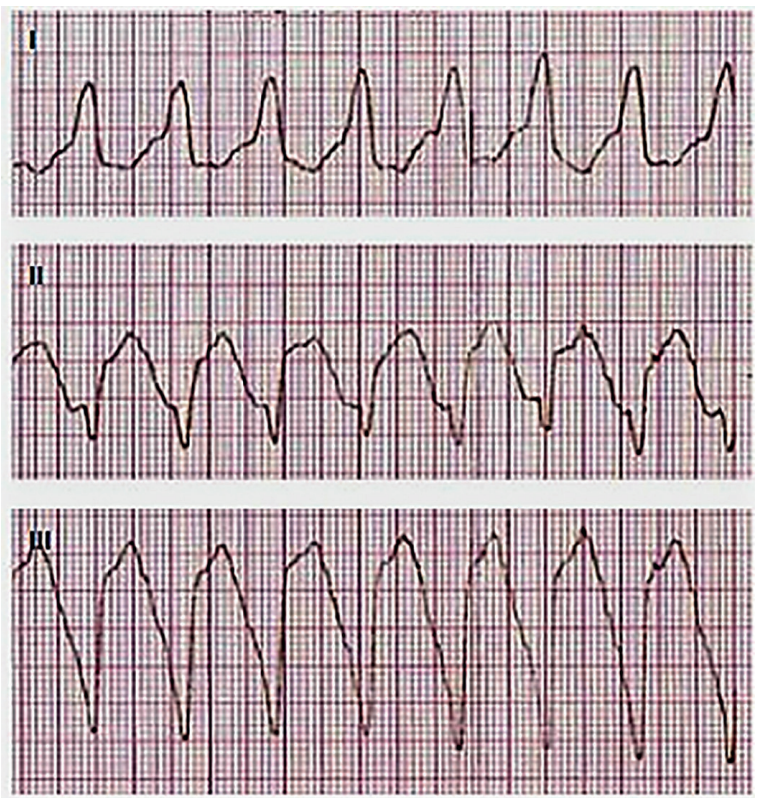

FIGURE 2. Ventricular tachycardia (VT)
FiO2 $10 \mathrm{l} / \mathrm{min}(\mathrm{SaO} 2$ 99\%) continues, while blood sugar is $151 \mathrm{mg} \%$.

Contact is made with interventional cardiology in order to obtain approval for the patient to be transported to the catheter lab (with no previous data transmission). After collecting his medical history, the doctor on duty agrees to admit the patient for urgent coronary catheterization.

While being prepared for transportation, the patient complains about chest pains for the first time. The pharmacotherapy previously initiated continues. The patient is transported to interventional cardiology and is transferred to the doctor at the catheter lab after 20 minutes in the ambulance. The transportation ran without complications, and the condition of the patient significantly improved: HR 90/min, steady sinus rhythm, chest pains increase.

The information from the interventional cardiology doctor (around 12:10) was as follows: critical closure of RCA and extensive atherosclerosis spread within the coronary arteries.

\section{DISCUSSION}

Ventricular tachycardia, which causes haemodynamic instability in a patient through a low cardiac output, is brought about by progressive cerebral hypoxia. Following cerebral hypoxia, a patient may develop aggressive behaviour towards people who are trying to provide him with necessary assistance. The development of hypoxia may contribute to the obliteration of one's picture of the surrounding world and criticism towards one's own health. Disturbances of consciousness and loss of consciousness hamper the quick implementation of $A B C D E$ and adequate treatment. The performance of such procedures as cannulation, for the purpose of administering life-saving medication, may prove impossible at this stage. Much depends on the substantial training and experience of the rescuing team. At this stage, the simple principle of "observing and reacting" becomes the team's most invaluable asset. The presented case study is the best indicator to demonstrate that the implementation of adequate procedures and therapies may not always be possible, regardless of the knowledge and involvement of the paramedics in saving a patient's life. The decision of which treatment should be administered is always made by the doctor or a paramedic in collaboration with the patient. The implementation of a procedure by simply putting into practice what has been 
put on paper may not always be possible in extreme situations. In such a situation, when the medical rescue team has limited powers of operation, the most desirable course of action is to resist the developing hypoxia, and the attempt to administer medicines or perform a quick electrical cardioversion preceded by analgosedation, in every manner possible. However, this issue raises several questions about the legality of all attempts that a paramedic makes to save a patient's life in a life-threatening situation, if the patient refuses to accept such assistance (while potentially being unconscious). Is the paramedic's responsibility on a par with that of a doctor's in such a situation?

In the presented case study, although the patient was showing signs of aggressive behaviour, the team were trying to calm him down and explain the purpose of the actions taken. The question arises whether such behaviour, and possibly delaying of the electrical cardioversion, might potentially be a cause of death and the subject of a lawsuit in the future. Aggression on the part of the patient often provokes the use of unconventional methods.

Facing such a multitude of questions, which often remain unanswered, one must conclude that the actions of a medical rescue team in a situation as described above should consist of a persistent determination to oxygenate the blood, combat the symptoms of hypoxia and urgently perform electrical cardioversion. The description of the patient above becomes a perfect example of patience and consistency in continuing treatment and achieving the ultimate goal of saving the patient's life.

\section{CONCLUSIONS}

Ventricular tachycardia (VT), as one of the most dangerous cardiac dysrhythmias, may lead to extreme aggression in a patient, and an inability to use any type of treatment, even one that potentially saves lives. The ability to make decisions, consistency, combating hypoxia and continuing to maintain a conversation with the patient are the dominating factors in fighting the patient's misinterpretation of the situation and extreme aggressiveness. The preparation of a universal procedural algorithm in the occurrence of ventricular tachycardia with pulse should always contain some of the valuable tips concerning which elements need to be paid attention when attempting to implement adequate electrotherapy and pharmacotherapy. The decision to hand the patient over to the catheter lab followed from ERC 2015 recommendations. The guidelines recommend the performance of coronary catheterization and a possible percutaneous coronary intervention (PCI) in cases of out-of-hospital cardiac arrest, when a cardiac cause is suspected and the ST is elevated in ECG. Moreover, the performance of coronary catheterization and PCI is justifiable in patients without elevated ST section with high probability of a coronary cause of CA [10].

\section{Conflict of interest: None declared.}

\section{REFERENCES}

1. Zipes DP, Wellens HJ. Sudden cardiac death. Circulation. 1998; 98(21): 2334-2351, indexed in Pubmed: 9826323.

2. Trusz-Gluza M, Bednarkiewicz Z, Krupienicz A, et al. Częstoskurcz komorowy — podziały, mechanizmy, sposoby rozpoznawania i prognozowania [Ventricular tachycardia - divisions, mechanisms, ways of diagnosis and prognosis]. ESS. 1994; 1: 6.

3. Opolski G. Kardiologia - kompendium. PZWL, Warszawa 2016.

4. Pytkowsk M. Podstawy EKG, zaburzenia automatyzmu i przewodzenia, tachyarytmie. Medical Tribune Polska, Warszawa 2016.

5. German LD, Packer DL, Bardy GH, et al. Ventricular tachycardia induced by atrial stimulation in patients without symptomatic cardiac disease. Am J Cardiol. 1983; 52(10): 1202-1207, indexed in Pubmed: 6650408.

6. Trusz-Gluza M, Bednarkiewicz Z, Krupienicz A, et al. Specyfika częstoskurczu komorowego w zależności od schorzenia podstawowego [Specificity of ventricular tachycardia depending on the basic disease]. ESS. 1999; 3: 80.

7. Dąbrowska B, Dąbrowski A. Podręcznik elektrokardiografii. PZWL, Warszawa 1999: 105-107.

8. https://www.slideshare.net/Firedemon13/cardiac-conduction-system (06.10.2017).

9. The Regulation of the Minister of Health of 20 April 2016, item 587, on medical rescue operations and health services other than rescue operations which may be provided by the paramedic.

10. Jankowski M, Cebula G. Resuscytacja krążeniowo-oddechowa według wytycznych European Resuscitation Council 2015:część IV: opieka poresuscytacyjna. Med Prakt. 2016; 4: 16-35. 